\title{
OXIDATIVE CHANGES AND COGNITIVE FUNCTION DECLINE IN AGING RATS
}

\section{MUHAMMAD IRFAN NORMAN FRANCIS RUDIN, SUZANA MAKPOL, WAN ZURINAH WAN NGAH, YASMIN ANUM MOHD YUSOF*}

Department of Biochemistry, Level 17, Pre-Clinical Building, Faculty of Medicine, Universiti Kebangsaan Malaysia, Jalan Ya'acob Latif, Bandar Tun Razak, 56000 Cheras, Kuala Lumpur, Malaysia. Email: rahmatyasmin@yahoo.com

Received: 16 October 2018, Revised and Accepted: 06 December 2018

ABSTRACT

Objective: This study aims to show that impairment of cognitive function occurred during aging is related to increased oxidative stress.

Methods: A total of 36 Sprague Dawley rats were divided into four groups: Young (3 months), middle (14 months), and old age groups (18 and 23 months). Rats were killed and blood was collected for the measurement of oxidative stress which includes deoxyribonucleic acid (DNA) damage and lipid peroxidation (malondialdehyde [MDA] levels). Cognitive function of rats was measured through open-field experiments, Morris water maze (MWM), and object identification.

Results: Increased DNA damage and MDA levels were found in middle age and old rats compared to young rats ( 3 months old, $\mathrm{p}<0.05$ ). There was an increase in anxiety with age as indicated by the increased production of fecal boli and decreased activity of grooming and rearing. For the navigation test, older rats took a long time to search for the hidden platform compared to young rats. In the probe test (spatial memory test $24 \mathrm{~h}$ after the last training), the middle- and old-age groups spent less time at the quadrant compared to the young age group.

Conclusion: There is a decline in cognitive function with increased oxidative stress in aging rats.

Keywords: Aging rats, Oxidative stress, Morris water maze, Cognitive decline.

(C) 2019 The Authors. Published by Innovare Academic Sciences Pvt Ltd. This is an open access article under the CC BY license (http://creativecommons. org/licenses/by/4. 0/) DOI: http://dx.doi.org/10.22159/ajpcr.2019.v12i2.30127

\section{INTRODUCTION}

Globally, a growing number of older people have become a major concern in social and health issues. It has been estimated that the worldwide population of people aged 65 and older will triple to 1.5 billion by 2050 which is equivalent to $16 \%$ of the worldwide population [1]. Although a growing aging population may indicate a healthier generation with modern care medicine, it may also suggest the increasing incidence of aging-associated neurodegenerative disorders such as Alzheimer's disease (AD) and Parkinson's disease [2]

Aging can be defined as a gradual and continuous process of natural change (physical and mental capabilities) accompanied by a decline in organ function that occurs in early adulthood and the deterioration of body's functions during old age [3]. There are many theories that postulate the mechanism of aging and two major theories include deoxyribonucleic acid (DNA) damage and the free radical theory [4]. It is known that DNA damage occurs continuously and is repaired by DNA polymerase and other mechanisms; however, due to increasing age, these mechanisms can no longer repair the defects which result in the cellular senescence or apoptosis during aging [5,6]. A meta-analysis study by Soares et al. [7] showed that there is an association between age and DNA damage in humans. The free radical theory introduced by Harman [8] defines that accumulation of free radicals such as hydroxyl radical, hydroxyl ion, superoxide ion, and hydrogen peroxide will disrupt the function of all cell components such as nucleic acids, lipids, and proteins $[9,10]$. An imbalance between free radical generation and antioxidant ability to scavenge free radicals will result in oxidative stress leading to oxidative damage to lipids, proteins, ribonucleic acid, and DNA. Oxidative damage to these biomolecules can contribute to loss of function of most organs including the brain which is particularly susceptible to oxidative damage due to its high oxygen consumption rate, its high-energy demands, and rich abundance of polyunsaturated fatty acids and lipids relative to other organs [11,12]. Changes in antioxidant enzyme activity with age, for example, superoxide dismutase, glutathione peroxidase, and catalase have been unequivocal, depending on species of animals and organs studied [13].

Cognitive change is a normal process in aging. Although some cognitive abilities improve with aging, such as the vocabulary, other abilities, such as conceptual reasoning, memory, and processing speed, decline gradually over time [14]. Spatial learning [15] and memory [16,17] are particularly vulnerable to an age-related decline in humans. A decline in memory will have a great impact on the quality of life with advancing age, especially the ability to live independently without having to depend on caretakers [18]. Morris water maze (MMZ) invented by Morris [19] is popularly applied in assessing mouse and rat models for elucidating normal and pathological processes that influence learning and memory [20-22]

Increasing evidence has implicated free radical production and resultant oxidative damage as a major contributing factor in brain aging and cognitive decline [11,23-25]. Berr et al. [26] demonstrated that not only there was a cognitive decline associated with systemic oxidative stress among 1166 subjects aged between 60 and 70 but also a decrease in plasma antioxidant selenium level. In this study, we attempted to evaluate the cognitive and behavioral functions and the levels of oxidative stress in aging rats.

\section{METHODS}

Animals

This study was carried out in strict accordance with the recommendations in the Guide for the Care and Use of Laboratory Animals of the Universiti Kebangsaan Malaysia. A total of 36 male Sprague Dawley rats were divided into young (3 months old), middle age (14 months), and old groups (18 months and 23 months). They were fed with standard rat chow (Gold Coin, Malaysia) and tap water 
ad libitum. Animals were housed with one animal per cage at room temperature under a $12 \mathrm{~h}$ dark: light cycle. This study was approved by the National University of Malaysia Animal Ethics Committee, FP/BIOK/2013/ZURINAH/509-May-2013-May-2016. Every effort was made to limit the number of animals used and to reduce their suffering.

\section{Open field}

This test was used to evaluate locomotor activity, exploration, and anxiety. A dark-colored wooden box $(60 \mathrm{~cm} \times 60 \mathrm{~cm})$ with $20 \mathrm{~cm}$ high wall was used according to a previous study with modifications $[25,26]$. Exploratory behavior was tested by placing rats into the open field chamber for $5 \mathrm{~min}$ and their behavior was recorded during the experiment. The number of fecal boli and number and duration of wallsupported rearing and grooming were analyzed using HVS Image 2014 software (HVS Image.UK).

\section{The object recognition task}

The experiment consisted of three stages: Habituation (days 1-2), reaction to a novel object (day 3 ), and reaction to displaced objects (days 4-5), and for each stage, the behavior of rats was recorded. The rats were allowed to acclimatize for at least 20-30 min before beginning the experiment. For the habituation phase, the rats were placed into a chamber containing four objects of similar size $(4 \mathrm{~cm} \times 5 \mathrm{~cm})$, and they were allowed to explore the objects for $5 \mathrm{~min}$ and let rest for about $30 \mathrm{~min}$ in a holding box. In Stage 2, the rats were placed back into the chamber again for $5 \mathrm{~min}$ and then returned to its home cage. This test procedure was repeated on day 2 . On day 3 , one of the familiar objects was replaced with a novel object. The time spent exploring the novel and familiar objects was recorded. On day 4 , the rats were subjected to habituation stage as was done on days 1 and 2. On day 5, the locations of two of the objects were swapped, to test for reactions to the change. The time spent exploring the displaced and non-displaced objects was recorded, and object exploration was defined as when the rat's nose was within $2 \mathrm{~cm}$ of the object but not when the rat was sitting on the object or circling around it [27].

\section{MWM}

The MWM was used to evaluate spatial learning and memory. A black circular galvanized pool ( $140 \mathrm{~cm}$ diameter and $50 \mathrm{~cm}$ deep), filled with tap water at $24^{\circ} \mathrm{C}\left( \pm 2^{\circ} \mathrm{C}\right)$ to the depth of $30 \mathrm{~cm}$, was used. The pool was divided into four equal quadrants and a platform $(13 \mathrm{~cm} \times 13 \mathrm{~cm})$ was placed in the center of one of the quadrants (target quadrant) $2 \mathrm{~cm}$ below the water surface. The laboratory light and several prominent visual features on the walls were held constant throughout the task. This test was conducted within 8 consecutive days: Place navigation (days 1-6), the probe test (day 7), and cued navigation (day 8).

\section{Place navigation}

During this test, the rats were trained to find the fixed hidden platform. It was carried out in six consecutive days as described by Liu et al. [27] and Taridi et al. [28] with some modifications. On the $1^{\text {st }}$ day, the animals were trained to find the position of a fixed, hidden platform. A total number of six trials were conducted per day. Rats were gently lowered in the water with tail first, facing the wall of the tank, sequentially from four different entry points. Once the rats found the platform, they were allowed on it for 10 . Then, the rats were rested in the holding cage for $120 \mathrm{~s}$ before proceeding to the next trial. If the rats successfully located the platform before 60 $s$, they were immediately removed from the pool, while those that failed to locate the platform within $60 \mathrm{~s}$, they were gently guided on to the platform. At the end of training sessions, rats were completely dried and returned to their warm home cage. The tests were repeated for the next 5 days. The following parameters were recorded: Escape latency (EL) (s), swim path or distance travelled (DT) (m), and swim speed (SS) $(\mathrm{m} / \mathrm{s})$. The time required for individual rats to find the platform and the length of the swim path was measured using a digital camera and a computer system to record movement (Microsoft LifeCam Studio ${ }^{\mathrm{TM}}$ Webcam, Sandyford Industrial Estate, Dublin, UK).

\section{Probe test}

This task was to evaluate spatial memory in rats, $24 \mathrm{~h}$ after the last training session (day 7). This test was repeated twice for each rat. The percentage of time that the rat spent in the target quadrant and the number of platform crossings in probe 1 (the first time, the rat was tested without a platform) and probe 2 (the second time, the rat was tested without a platform) was measured. The rats were then released into the water at a fixed starting point opposite side of the removed platform location and allowed to swim freely for $60 \mathrm{~s}$. The starting point was the same for all animals. The percentage of time spent in the target quadrant was measured.

\section{Cued navigation}

Cued navigation is a control test to ensure that the rat used in this study has an intact vision. This test was carried out on the day after completion of the probe test whereby the platform was moved to another quadrant and raised $2 \mathrm{~cm}$ above the water surface. To make the platform visible, the edge of the platform was marked by a colored masking tape. All rats were given six trials in a day with the maximum searching time of $60 \mathrm{~s}$, and once the platform was reached, they were allowed to be on the platform for $10 \mathrm{~s}$.

\section{DNA damage by comet assay}

Oxidative DNA damage was measured by the comet assay as described by Singh et al. [29], with slight modifications. Fully frosted microscope slides were covered with $80 \mu \mathrm{l} 0.6 \%$ normal melting point agarose (Sigma-Aldrich, St. Louise, MO, and USA) at $60^{\circ} \mathrm{C}$. Slides were covered immediately with $24 \mathrm{~mm} \times 40 \mathrm{~mm}$ coverslips. The slides were placed on an ice-cold flat tray to allow the agarose to solidify. An amount of $5 \mu \mathrm{l}$ of whole fresh blood was mixed with $70 \mu \mathrm{l}$ of $0.6 \%$ low melting point agarose (Sigma-Aldrich, USA) at about $37^{\circ} \mathrm{C}$. The coverslips were carefully removed from the slides, and all the mixtures (cell suspension) in the

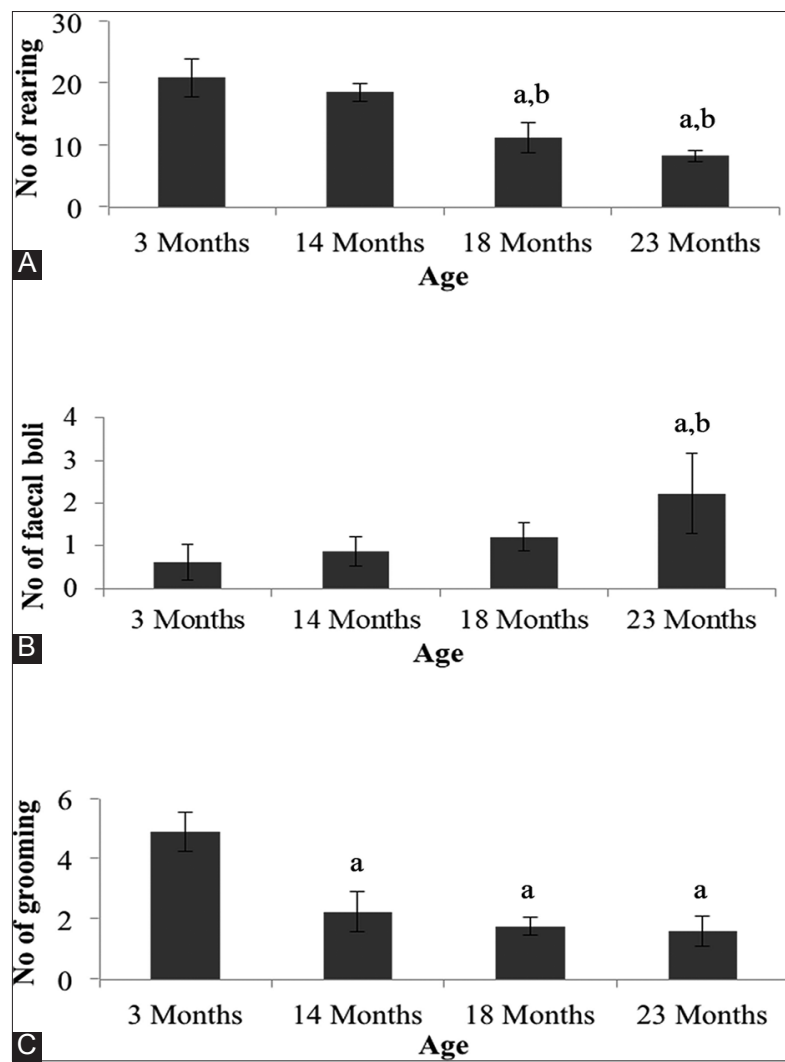

Fig. 1: Open-field parameters measured by (A) number of rearing, (B) number of fecal boli, (C) number of grooming in all age groups of rats a: Significant difference compared to 3 month-old rats $(p<0.05)$. b: Significant difference compared to 14-months-old rats $(\mathrm{p}<0.05)$ 
microcentrifuge tube were immediately pipetted onto a normal point agarose layer on a glass slide, covered using a coverslip, and allowed to solidify. The slide was then immersed in cold lysing solution $(2.5 \mathrm{M} \mathrm{NaCl}$, $100 \mathrm{mM} \mathrm{Na}{ }_{2}$ EDTA-2 $\mathrm{H}_{2}$ O, $10 \mathrm{mM}$ Tris, $1 \%$ sodium N-lauroyl sarcosinate, $1 \%$ Triton $\mathrm{X}-100,10 \%$ dimethyl sulfoxide, $\mathrm{pH} 10$ ) at $4^{\circ} \mathrm{C}$ for $1 \mathrm{~h}$. The slide was then placed in electrophoresis buffer $(0.3 \mathrm{M} \mathrm{NaOH}$ and $1 \mathrm{mM}$ $\mathrm{Na}_{2}$ EDTA) for 20 min to unwind the DNA. Electrophoresis was carried out at $4^{\circ} \mathrm{C}, 25 \mathrm{~V}$, and $300 \mathrm{~mA}$ for $40 \mathrm{~min}$. The slide was then neutralized with $0.4 \mathrm{M}$ Tris base buffer ( $\mathrm{pH}$ 7.5) twice and then drained. For visualization of comet tail, $30 \mathrm{ml}$ ethidium bromide $(20 \mu \mathrm{g} / \mathrm{ml})$ (Sigma-Aldrich, USA) was added; the slide was then covered with a new coverslip and placed in a humidified air-tight container in a refrigerator. Each slide was observed under the fluorescent microscope (objective $\times 20$ ) KS300 version 3.0 (Zeiss, Germany). An amount of 500 randomly selected non-overlapping cells on each slide were analyzed by categorizing cells according to an arbitrary scale of 0 to 4 based on perceived comet tail length migration and relative proportion of DNA in the comet tail as undamaged cells without tail (Score 0), cells with tiny tail (Score 1), cells with a dim tail (Score 2), cells with a clear tail (Score 3), and cells will maximum damage (Score 4). For final analysis, total damage score of each slide was calculated using the following formula: Arbitrary unit=Score 0 (n)+score 1 (n)+score $2(n)+$ score $3(n)+$ score $4(n)$; where $n=$ the number of cells categorized to each grade of damage.

\section{Lipid peroxidation}

Estimation of plasma malondialdehyde (MDA) levels was carried out as described by Sim et al. [30] based on the derivatization of MDA with 2,4-dinitrophenylhydrazine (DNPH) and its conversion into pyrazole and hydrazine derivatives. High-performance liquid chromatography (HPLC) analyses were performed on a LC-10 AT VP SHIMADZU (Kyoto, Japan) liquid chromatography system with a photodiode array detector and an auto-injection valve. MDA levels were expressed as nmol/l from the calibration curves. 1, 1, 3, 3-tetraethoxypropane (Sigma-Aldrich, USA) was used as the MDA standard. The mobile phase consists of

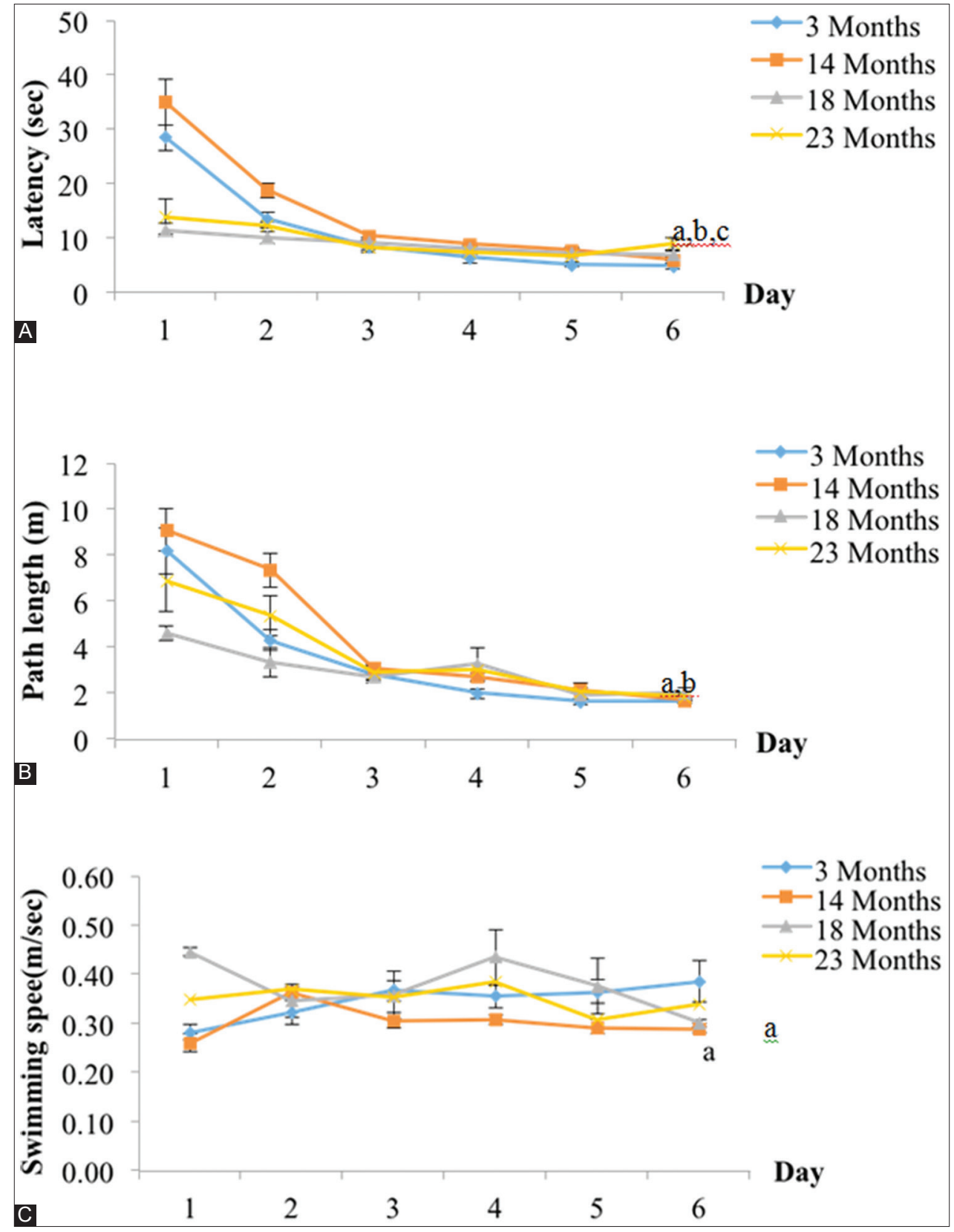

Fig. 2: Place navigation as measured by (A) time taken to reach platform, (B) distance travelled to the target platform, and (C) swim speed in all age groups of rats. a: Significant difference compared to 3 -month-old rats $(\mathrm{p}<0.05)$. b: Significant difference compared to 14 -monthold rats $(p<0.05)$. c: Significant difference compared to 18 -month-old rats $(p<0.05)$ 
$0.2 \%(\mathrm{v} / \mathrm{v})$ acetic acid in milli-Q water and acetonitrile $(62: 38)(\mathrm{v} / \mathrm{v})$ at a flow rate of $1.5 \mathrm{ml} / \mathrm{min}$. Briefly, $50 \mathrm{ml}$ of plasma was mixed with $200 \mathrm{ml}$ of $1.3 \mathrm{M} \mathrm{NaOH}$ and incubated at $60^{\circ} \mathrm{C}$ for $1 \mathrm{~h}$. After incubation, an amount of $100 \mathrm{ml}$ of $35 \%$ perchloric acid was added to the mixture and centrifuged at $10,000 \mathrm{~g}$ for $10 \mathrm{~min}\left(4^{\circ} \mathrm{C}\right)$. An amount of $300 \mathrm{ml}$ of the supernatant was transferred into $1.5 \mathrm{ml}$ HPLC tube plus $50 \mathrm{ml}$ of 5 mM DNPH and left for 30 min in the dark before detection by HPLC at $310 \mathrm{~nm}$.

\section{Statistical analysis}

All data are expressed as the mean \pm standard error mean. For each task in cognitive function test, data files created by the HVS software (HVS Image, UK) were exported to Microsoft Excel and SPSS (v. 20) for analysis. Statistical differences among more than three groups were estimated by one-way ANOVA followed by Bonferroni post hoc tests for multiple comparisons. Student's $t$-tests were used to compare the novel and familiar objects as well as displaced and non-displaced objects within each group. ${ }^{*} \mathrm{p}<0.05$ was considered to be statistically significant.

\section{RESULTS}

\section{The open-field test}

The number of rearing activity is significantly higher in young rats (3 months old, $20.87 \pm 3.08, \mathrm{p}<0.05$ ) and middle age rats (14-month-old rats, $18.42 \pm 1.49, \mathrm{p}<0.05)$ compared to older rats $(18$-month-old rats, $11.17 \pm 2.47)$ and (23-month-old rats, $8.17 \pm 0.98$ ) (Fig. 1a). The number of fecal boli in old group (23-month-old rats, $2.23 \pm 0.94$ ) was significantly higher compared to the young (3-month-old rats, $0.63 \pm 0.42$ ) and middle age groups (14-month-old rats, $0.88 \pm 0.34$, p<0.05) (Fig. 1b). The number of grooming showed a reduced tendency in middle age (14-month-old rats, $2.22 \pm 0.68$ ) and older groups (18-month-old rats, $1.75 \pm 0.31$, and 23 -month-old rats, $1.60 \pm 0.51$ ) compared to 3-monthold rats $(4.88 \pm 0.67, \mathrm{p}<0.05)$ (Fig. 1c).

\section{The MWM task}

For the first 5 days, assessment of learning consisted of the measurement of EL time, DT, and SS. Finally, on the $6^{\text {th }}$ day, spatial memory was assessed using the probe test. ET represented the time spent for rats to reach a hidden platform. The test was conducted for 5 consecutive trial days. ET decreased over the 6 days' training period for all age groups. However, the ET to reach hidden platform was significantly higher in older rats (23-month-old rats, $8.842 \pm 1.177 \mathrm{~s}$, and 18 -month-old rats, $6.942 \pm 0.5915 \mathrm{~s}$ ) (Fig. 2a) compared to the young group (3-monthold rats, $4.756 \pm 0.147 \mathrm{~s}, \mathrm{p}<0.05)$ and middle age rats (14-month-old rats, $5.890 \pm 0.2913 \mathrm{~s}, \mathrm{p}<0.05$ ) on day 6 . The DT to reach the platform in the middle age group (18 month-old rats) was significantly longer $(1.85 \pm 0.23 \mathrm{~m})$ compared to the young group $(1.67 \pm 0.08 \mathrm{~m}, \mathrm{p}<0.05)$ and the middle age group (14-month-old rats, $1.69 \pm 0.08 \mathrm{~m}, \mathrm{p}<0.05)$ (Fig. 2b). The SS for the middle age group (14-month-old rats, $0.29 \pm 0.01 \mathrm{~m} / \mathrm{s}$ ) was significantly slower compared to the young group $(0.34 \pm 0.04 \mathrm{~m} / \mathrm{s}, \mathrm{p}<0.05)$ (Fig. 2c).

To assess spatial memory, a probe trial was administered on training day 7, where the platform was removed from the pool and the rat was allowed to search for it in $60 \mathrm{~s}$. The percentage of time spent in the target quadrant (PTQ) of 18-month-old rats $(20.22 \pm 1.57 \%)$ and 23-monthold rats $(19.22 \pm 5.98 \%)$ was significantly lower compared to 14 -monthold rats $(29.14 \pm 2.04 \%<0.05)$ and 3 -month-old rats $(30.20 \pm 1: 15 \%$, $\mathrm{p}<0.05$ ) in the first probe test (Fig. 3a). On the second probe test, $2 \mathrm{~min}$ after a re-run of a repeat navigation session on the same day, it showed that PTQ in older rats (18-month-old rats, $19.89 \pm 2.76 \%$, and 23 -monthold rats, $15.31 \pm 2.13 \%$ ) was significantly lower compared to 14 -monthold rats $(28.40 \pm 9.2 \%, \mathrm{p}<0.05)$ and 3 -month-old rats $(35.09 \pm 3.59 \%$, p $<0.05$ ) (Fig. 3b).

In the cued navigation task, the EL time in older and middle age rats (14-month-old rats [4.98 $\pm 0.45 \mathrm{~s}], 18$-month-old rats [5.49 $\pm 0.20 \mathrm{~s}]$, and 23 -month old rats [ $5.73 \pm 0.15 \mathrm{~s}])$ was significantly longer compared to the young rats (3-month-old rats, $3.72 \pm 0.44 \mathrm{~s}, \mathrm{p}<0.05$ ) (Fig. 4).

\section{The object recognition}

The time of exploring novel objects (TEN) for the middle age (14-monthold rats, $5.94 \pm 0.31 \mathrm{~s}$ ) and old age groups (18-month-old rats, $2.75 \pm 0.82$ $\mathrm{s}$, and 23 -month-old rat, $1.78 \pm 0.04 \mathrm{~s}$ ) was significantly less than the young group $(18.25 \pm 0.20 \mathrm{~s}, \mathrm{p}<0.05)$ (Fig. $5 \mathrm{a})$. As for recognizing a familiar object, only the middle age group (18-month-old rats, $3.55 \pm 0.71$ ) spent significantly less time in exploring it compared to the young group $(9.69 \pm 3.02 \mathrm{~s}, \mathrm{p}<0.05)$. The time taken exploring displaced objects was significantly shorter in the middle age group (14-monthold rats, $3.77 \pm 0.54 \mathrm{~s}$ ) and older groups (18-month-old rats, $1.95 \pm 0.45$ $\mathrm{s}$, and 23-month-old rats, $2.66 \pm 1.22 \mathrm{~s}$ ) compared to the young group (16.01 $\pm 3.69 \mathrm{~s}, \mathrm{p}<0.05)$ (Fig. 5b). Similarly, the time taken to explore non-displaced object showed that the middle age (14-month-old rats, $3.03 \pm 0.23 \mathrm{~s}$ ) and the older groups (18-month-old rats, $1.89 \pm 0.80 \mathrm{~s}$, and 23-month-old rats, $4.96 \pm 2.00 \mathrm{~s})$ spent significantly shorter time compared to the young group $(9.69 \pm 3.02 \mathrm{~s}, \mathrm{p}<0.05)$ (Fig. $5 \mathrm{~b})$.

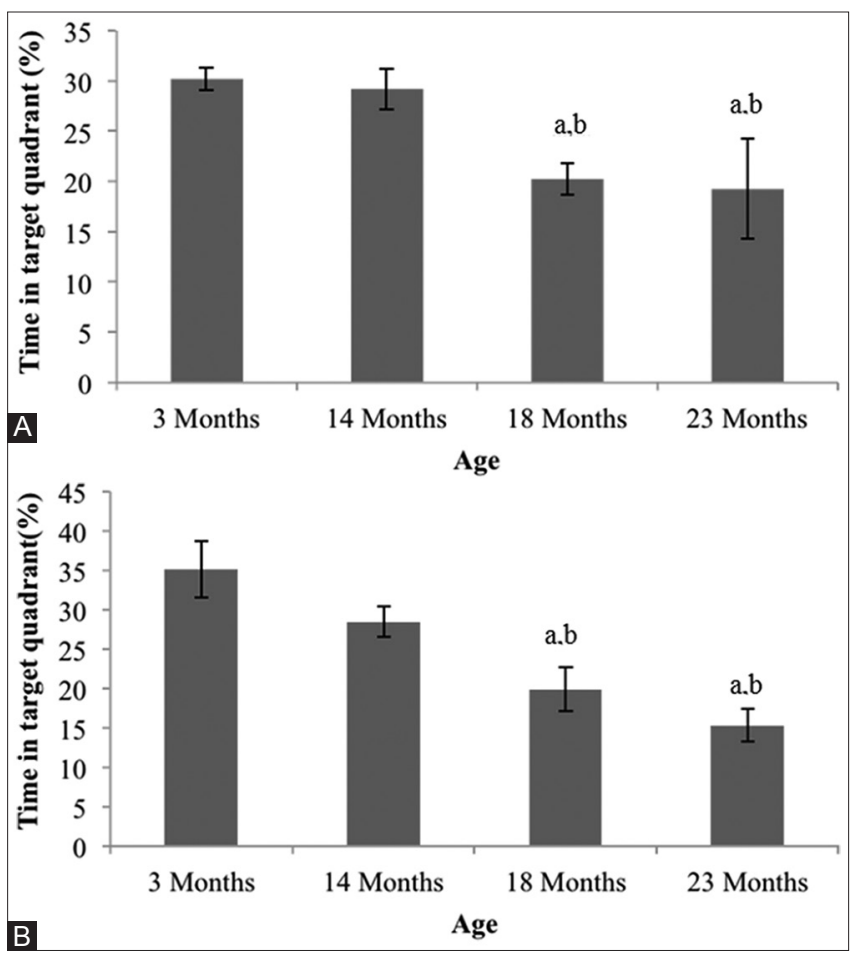

Fig. 3: Probe test parameters as measured by a percentage of time in target quadrant (A) first probe test and (B) second probe test in all age groups of rats. a: Significant difference compared to 3-month-old rats $(p<0.05)$. b: A significant difference compared to 14-month-old rats $(\mathrm{p}<0.05)$

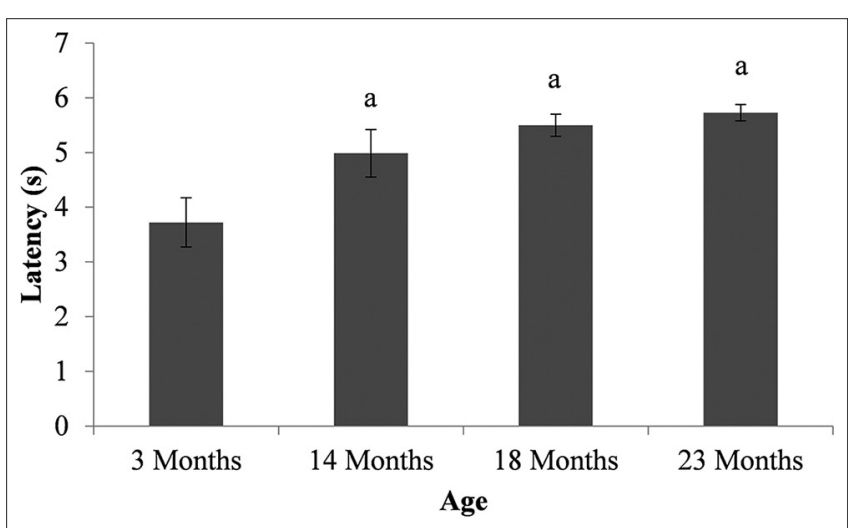

Fig. 4: Cued navigation parameter as measured by latency to platform in all age groups of rats. a: Significant difference compared to 3 -month-old rats $(p<0.05)$ 


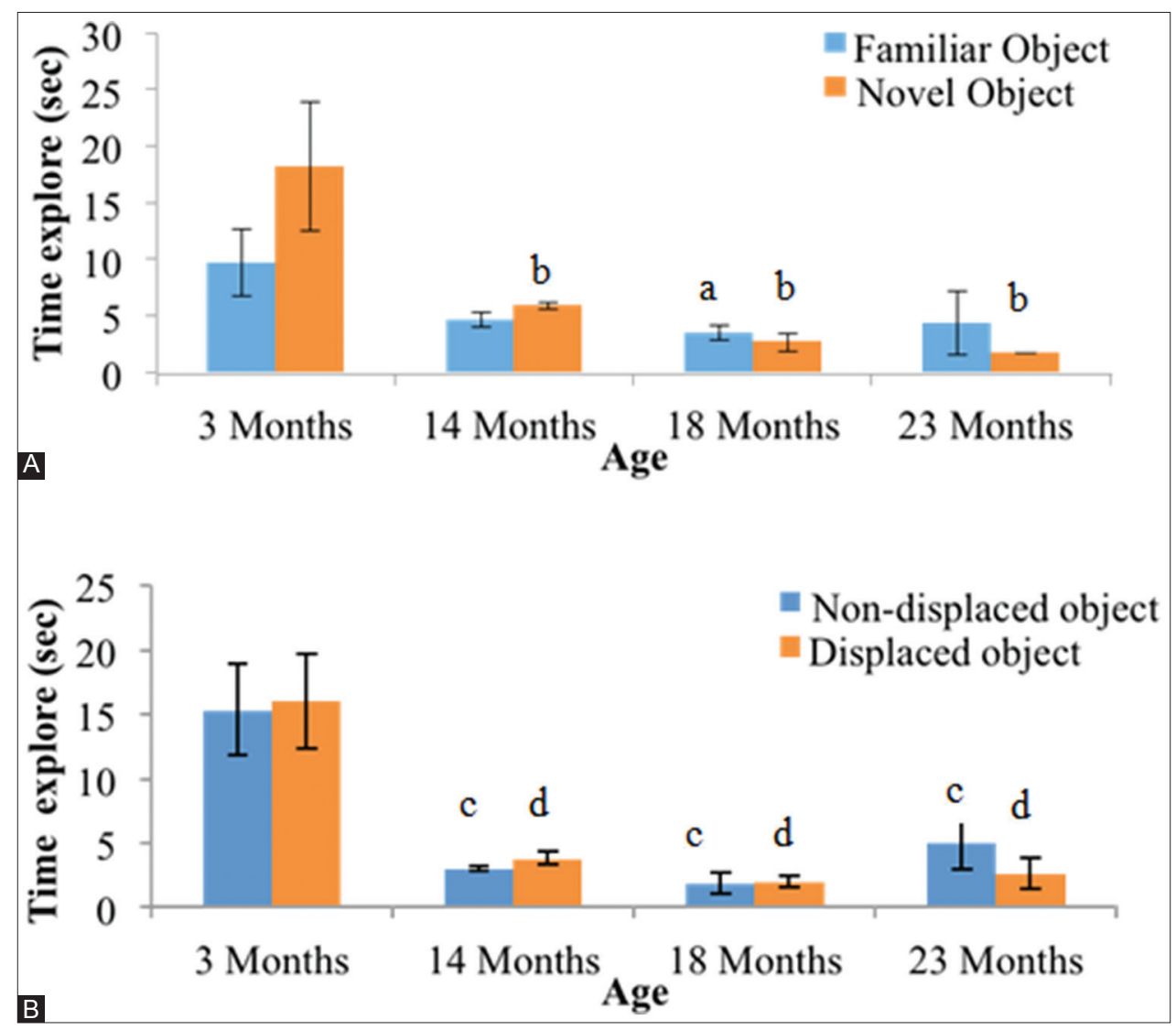

Fig. 5: Object recognition parameters measured by time in exploring of (A) novel object and (B) displaced object in all age groups of rats. a: Significant difference compared to 3-month-old rats familiar object $(p<0.05)$. b: Significant difference compared to 3-month-old rats novel object $(p<0.05)$. c: Significant difference compared to 3-month-old rats non-displaced object $(p<0.05)$. d: Significant difference compared to 3-month-old rats displaced object $(\mathrm{p}<0.05)$.

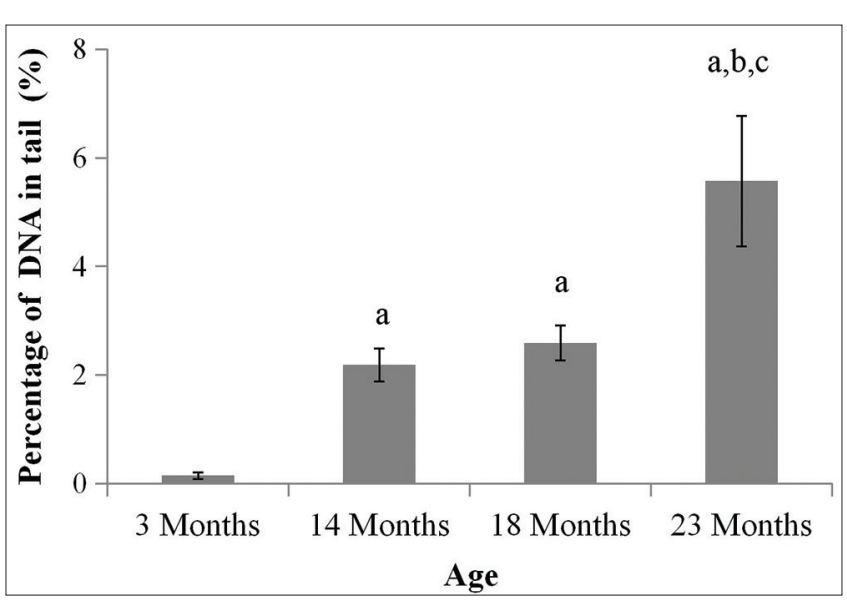

Fig. 6: DNA damage as measured by percentage of DNA in tail in all age group of rats. a: significant difference compared to 3 month-old rats $(p<0.05)$. b:A significant difference compared to 14 month-old rats $(\mathrm{p}<0.05)$.c: significant difference compared to 18 month-old rats $(\mathrm{p}<0.05)$.

\section{Percentage DNA damage}

Oxidative stress is reflected by the elevated level of total percentage DNA damage in the oldest group (23-month-old rats, $5.57 \pm 1.2 \%$ ) compared to the young group (3-month-old rats, $0.15 \pm 0.06 \%, \mathrm{p}<0.05$ ) and the middle age group (14-month-old rats, $2.18 \pm 0.30 \%, \mathrm{p}<0.05)$ (Fig. 6).

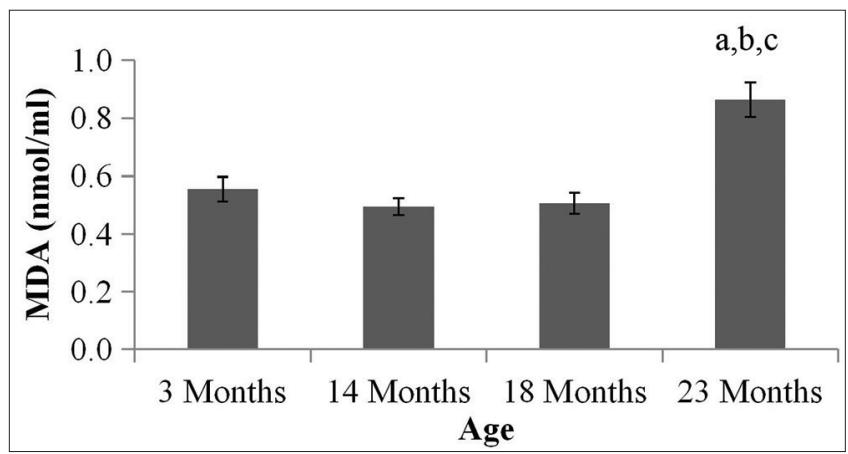

Fig. 7: Plasma malondialdehyde (MDA) in all age group of rats. a: significant difference compared to 3 month-old rats $(p<0.05)$. b: significant difference compared to 14 month-old rats $(p<0.05)$. c: significant difference compared to 18 month-old rats $(p<0.05)$.

Lipid peroxidation

Oxidative stress is reflected by an increase in plasma MDA level in the oldest group (23-month-old rats, $0.86 \pm 0.06 \mathrm{nmol} / \mathrm{ml}$ ) compared to the middle age (14-month-old rats, $0.49 \pm 0.03 \mathrm{nmol} / \mathrm{ml}, \mathrm{p}<0.05)$ and young groups (3-month-old rats, $0.55 \pm 0.04 \mathrm{nmol} / \mathrm{ml}, \mathrm{p}<0.05$ ) (Fig. 7).

\section{DISCUSSION}

The normal aging process is associated with a decline in certain cognitive abilities, such as processing speed, spatial learning and memory, and executive function abilities. There is an ample body of evidence to suggest that an age-related increase in oxidative stress in 
both humans and experimental animals is associated with cognitive decline [11,23-26]. Many physiological changes such as free radical production and resultant oxidative damage occur with age and can have major cognitive deficit such as spatial and temporal memory. Spatial memory relies on intact hippocampal function. Temporal memory may also be associated with the hippocampus, although it may be more closely associated with the striatum and cerebellum. The purpose of this study was to determine whether there is a cognitive deficit in aged rats associated with oxidative damage.

The open-field tasks reflected the exploratory, anxiety, and locomotor activity of rodents based on the natural tendency for them to explore novel environments. Aged rats in our study were seen to be more anxious as indicated by increased excretion of fecal boli and fewer walls supported rearing. This behavior was also noted by Taridi et al. [28], but tocotrienol-rich fraction (TRF) supplementation to the aged rats reduces their anxiety level and increases their exploratory activity.

Rats can be considered as excellent swimmers since they are motivated to escape from the water. Once they learn where the hidden platform is located, they can remember the location and swim rapidly to it from any starting point. The MWM has been extensively used to measure hippocampus-dependent cognitive deficits in spatial memory during aging [31]. Spatial memory encompasses knowledge of location within an environment. Impaired spatial ability can have a great impact on the quality of life with advancing age. For human and animal studies, spatial memory appears to be one of the earliest cognitive functions to decline with age $[16,32]$.

An interesting observation from MWM experiments was that the percentage of elapsed time (ET) spent and DT in the target quadrant decreased with days of training for all age groups. However, young rats spent a significantly shorter ET than old rats $(\mathrm{p}<0.05)$ in finding the hidden platform. The probe test was to determine if spatial memory was used to locate the hidden platform, and we found that aged rats spent less time in the target quadrant, suggesting the inability to remember which quadrant contained the platform. These results suggest that aged rats have poorer spatial memory when compared with young rats, which is consistent with a previous study $[27,30]$. Poorer performance on memory tasks by old rats could involve, in part, oxidative damage to DNA as seen in our study whereby the oldest rats (23 months old) showed a high percentage of DNA damage. Lipid peroxidation also increased in aged rats, as shown by the elevated levels of plasma MDA. On the contrary, we found that young and middle age rats spent significantly more time at the former platform position $(\mathrm{p}<0.05)$ than old rats did. Interestingly, the extent of DNA damage and lipid peroxidation in young rats was significantly less than in old rats. Similar findings were also observed by Taridi et al. [30], who also observed that TRF supplementation ameliorated the oxidative DNA damage and lipid peroxidation. Recent findings by Hajjar et al. [25] showed that oxidative stress reflected by a low or a progressive decrease in glutathione levels is associated with a decline in executive function among aged healthy adults.

The cued navigation test is used to measure deficits in vision, motivation, motor strength, or coordination on day 6 of the training cycle. The platform protruded $1 \mathrm{~cm}$ above the surface of the water. Young rats required less time to find the visible platform than the old animals. The object recognition test also confirmed that aged rats were less interested in exploring the novel and displaced objects. These results indicated impaired working memory in aged rats compared with young rats.

This study and other studies suggest that aging and neurodegenerative disease such as AD may be explained by the free radical theory [8], whereby accumulation of free radicals damages DNA and causes lipid peroxidation. Interestingly, a study by Lovell and Markesbery [11] showed an elevated level of 8-OHG, 8-OHA, and 5, 6-diamino5 -formamidopyrimidine in both nuclear and mtDNA isolated from brain regions of mild cognitive impaired subjects, the earliest clinical manifestation of AD. Meramat et al. [33] showed that a total of $62.1 \%$ of subjects above 60 years old had cognitive impairment, and among them, there are significantly higher levels of MDA and DNA damage as compared to the group with normal cognitive function.

The modulatory effects of antioxidant rich-dietary components on cognitive function have been elucidated by many studies. Taridi et al. [28] showed that TRF supplementation to aging rats reduced markedly level of anxiety, improved spatial learning and memory, reduced amount and severity of DNA damage, reduced level of MDA, and increased levels of antioxidant enzyme activity and plasma/ brain Vitamin E compared with age-matched controls. In another study, TRF supplementation reversed age-associated changes in arginine metabolites in the entorhinal cortex and cerebellum of rats [34].

\section{CONCLUSION}

Our study showed that aged rats exhibited reduced exploratory activity, enhanced anxiety, decreased spatial learning and memory, and increased DNA damage and plasma MDA levels compared with young rats

\section{ACKNOWLEDGMENTS}

We are indebted to the postgraduate students Nurul Aliah Acin, Nurul Izzati Abdul Rahim, Wan Nurzulaikha Wan Nasri, and the staff of the Department of Biochemistry, Faculty of Medicine, UKM, for the technical help rendered in this project.

\section{FINANCIAL DISCLOSURE}

The authors declared that this study has received financial support from Universiti Kebangsaan Malaysia. This work has been financially supported by the LRGS/BU/2012/UKM-UKM/04 and DIP-2013-003

\section{AUTHORS' CONTRIBUTIONS}

Concept - YAMY, SM, and WZWN; design - YAMY and WZWN; supervision - YAMY and SM; data collection and/or processing - MINFR; analysis and/or interpretation - MINFR and YAMY; literature search - MINFR; and writing - MINFR, YAAMY, SM, and WZWN.

\section{CONFLICTS OF INTEREST}

No conflicts of interest were declared by the authors.

\section{REFERENCES}

1. Suzman R, Beard J. Global Health and Aging. National Institute on Aging, National Institutes of Health, U.S Department of Health and Human Services; 2011. NIH Publication Number: 11-7737.

2. United Nations. World Population Ageing. New York: United Nations; 2013.

3. Ureshino RP, Rocha KK, Lopes GS, Bincoletto C, Smaili SS. Calcium signaling alterations, oxidative stress, and autophagy in aging. Antioxid Redox Signal 2014;21:123-37.

4. Harman D. Aging: A theory based on free radical and radiation chemistry. J Gerontol 1956;11:298-300.

5. Jin K. Modern biological theories of aging. Aging Dis 2010;1:72-4.

6. Chen JH, Hales CN, Ozanne SE. DNA damage, cellular senescence and organismal ageing: Causal or correlative? Nucleic Acids Res 2007;35:7417-28.

7. Soares JP, Cortinhas A, Bento T, Leitão JC, Collins AR, Gaivão I, et al. Aging and DNA damage in humans: A meta-analysis study. Aging (Albany NY) 2014;6:432-9.

8. Harman D. The biologic clock: The mitochondria? J Am Geriatr Soc 1972;20:145-7.

9. Sanz A, Stefanatos RK. The mitochondrial free radical theory of aging: A critical view. Curr Aging Sci 2008;1:10-21.

10. Jacobs HT. The mitochondrial theory of aging: Dead or alive? Aging Cell 2003;2:11-7.

11. Lovell MA, Markesbery WR. Oxidative DNA damage in mild cognitive impairment and late-stage Alzheimer's disease. Nucleic Acids Res 
2007;35:7497-504

12. Sushama P, Manmohini J. Effect of bacoside a on lipid peroxidation in d-galactose induced aging mice. Int J Pharm Pharm Sci 2017;9:12-5.

13. Kitani K. What really declines with age? The hayflick lecture for $200635^{\text {th }}$ American aging association. Age (Dordr) 2007;29:1-4

14. Harada CN, Natelson Love MC, Triebel KL. Normal cognitive aging. Clin Geriatr Med 2013;29:737-52.

15. Newman MC, Kaszniak AW. Spatial memory and aging: Performance on a human analog of the Morris water maze. Aging Neuropsychol Cogn 2000;7:86-93.

16. de Jager CA, Milwain E, Budge M. Early detection of isolated memory deficits in the elderly: The need for more sensitive neuropsychological tests. Psychol Med 2002;32:483-91.

17. West RL, Welch DC, Knabb PD. Gender and aging: Spatial self-efficacy and location recall. Basic Appl Soc Psychol 2002;24:71-80.

18. Foster TC, Defazio RA, Bizon JL. Characterizing cognitive aging of spatial and contextual memory in animal models. Front Aging Neurosci 2012;4:12.

19. Morris R. Developments of a water-maze procedure for studying spatial learning in the rat. J Neurosci Methods 1984;11:47-60.

20. Barnhart CD, Yang D, Lein PJ. Using the morris water maze to assess spatial learning and memory in weanling mice. PLoS One 2015; 10:e0124521.

21. Maei HR, Zaslavsky K, Teixeira CM, Frankland PW. What is the most sensitive measure of water maze probe test performance? Front Integr Neurosci 2009;3:4

22. Torgal S, Sugato $\mathrm{CH}$. Effect of metformin and simvastatin in diazepamand sodium nitrite-induced anterograde amnesia in male Swiss albino mice. Int J Pharm Pharm Sci 2018;10:18-22.

23. Sack CA, Socci DJ, Crandall BM, Arendash GW. Antioxidant treatment with phenyl-alpha-tert-butyl nitrone (PBN) improves the cognitive performance and survival of aging rats. Neurosci Lett 1996;205:181-4.

24. Zhu Y, Carvey PM, Ling Z. Age-related changes in glutathione and glutathione-related enzymes in rat brain. Brain Res 2006;1090:35-44

25. Hajjar I, Hayek SS, Goldstein FC, Martin G, Jones DP, Quyyumi A, et al. Oxidative stress predicts cognitive decline with aging in healthy adults: An observational study. J Neuroinflammation 2018;15:17.

26. Berr C, Balansard B, Arnaud J, Roussel AM, Alpérovitch A. Cognitive decline is associated with systemic oxidative stress: The EVA study. Etude du vieillissement artériel. J Am Geriatr Soc 2000;48:1285-91.

27. Liu J, Head E, Gharib AM, Yuan W, Ingersoll RT, Hagen TM, et al. Memory loss in old rats is associated with brain mitochondrial decay and RNA/DNA oxidation: Partial reversal by feeding acetyl-L-carnitine and/or R-alpha-lipoic acid. Proc Natl Acad Sci U S A 2002;99:2356-61.

28. Taridi NM, Abd Rani N, Abd Latiff A, Ngah WZ, Mazlan M. Tocotrienol rich fraction reverses age-related deficits in spatial learning and memory in aged rats. Lipids 2014;49:855-69.

29. Singh NP, McCoy MT, Tice RR, Schneider EL. A simple technique for quantitation of low levels of DNA damage in individual cells. Exp Cell Res 1988;175:184-91.

30. Sim AS, Salonikas C, Naidoo D, Wilcken DE. Improved method for plasma malondialdehyde measurement by high-performance liquid chromatography using methyl malondialdehyde as an internal standard. J Chromatogr B Analyt Technol Biomed Life Sci 2003;785:337-44.

31. Issa AM, Rowe W, Gauthier S, Meaney MJ. Hypothalamic-pituitaryadrenal activity in aged, cognitively impaired and cognitively unimpaired rats. J Neurosci 1990;10:3247-54

32. Adams MM, Shi L, Linville MC, Forbes ME, Long AB, Bennett C, et al. Caloric restriction and age affect synaptic proteins in hippocampal CA3 and spatial learning ability. Exp Neurol 2008;211:141-9.

33. Meramat A, Rajab NF, Shahar S, Sharif RA. DNA damage, copper and lead associates with cognitive function among older adults. J Nutr Health Aging 2017;21:539-45

34. Mazlan M, Hamezah HS, Taridi NM, Jing Y, Liu P, Zhang H, et al. Effects of aging and tocotrienol-rich fraction supplementation on brain arginine metabolism in rats. Oxid Med Cell Longev 2017;2017:6019796. 